\title{
Há função pedagógica na publicidade?
}

Wanderson Claudio Da Silva

Centro Universitário UNA

sekaomestrado@gmail.com

Cláudio Márcio Magalhães

Centro Universitário UNA

claudio.marcio@prof.una.br

Forma de citar este artículo:

Da Silva, W. C. y Magalhães, C. M. (2019). “Há função pedagógica na publicidade?”, RAEIC, Revista de la Asociación Española de Investigación de la Comunicación, vol 6, núm. 11, 141-164. DOI:

\section{Resumo:}

O presente estudo tem como tema principal o estudo da função pedagógica da publicidade. A partir de uma pesquisa qualitativa e exploratória, buscou-se analisar e descrever o entendimento de publicitários e pedagogos de como a publicidade pode agir pedagogicamente. $\mathrm{O}$ artigo se insere no campo de estudo da educação e da publicidade e os resultados consideram o uso da publicidade como agente educativo e apresenta, ainda, aspectos teóricos e práticos da publicidade em consonância com a educação e o desenvolvimento local. Concluiu-se que, embora seu uso na educação formal ainda seja pouco explorado, a publicidade é uma importante ferramenta para atividades educacionais em geral. 
Palabras chave: Publicidade, educação, pedagogía, desenvolvimento local.

\section{Abstract:}

This study has as its main theme the study of the pedagogical function of advertising. From a qualitative exploratory study, we sought to analyze and describe the understanding of advertising and educators on how advertising can act pedagogically. This article is included in the education field of study and advertising and their interfaces with local development. The results of this study consider the use of advertising as an educational agent and also presents theoretical and practical aspects of advertising in line with the education and local development. It was concluded that, although its use in formal education is still little explored, advertising is an important tool for educational activities in general.

Keywords: Advertising, education, pedagogy, local development.

\section{INTRODUÇÃO}

A presente pesquisa tem como tema central o estudo da função pedagógica da publicidade, por ser esta uma ferramenta de grande penetração nos mais distintos grupos e classes sociais e estar presente em todas as camadas sociais. Além disso, pode ser usada de modo a se tornar uma ferramenta educativa. Portanto, a proposta do presente estudo é detectar se a publicidade possui caráter pedagógico e se ela pode, juntamente com a escola, criar novos meios e ferramentas para a educação.

Sendo assim, o problema central emerge quando se observa que as organizações, em geral e independentemente de suas configurações - privadas, públicas, organizações não governamentais (ONGs) -, utilizam a publicidade como um instrumento de comunicação. Neste sentido, ela Ihes serve como ferramenta de "venda" - produto, serviço, ideias, desejos -, na tentativa de criar uma posição favorável à sua marca e intenções. Para isso, entre várias estratégias, emprega-se, principalmente, o discurso persuasivo. Levando-se em consideração o conceito de Roiz (apud Fischer, 2007, p. 2), o discurso persuasivo não é apenas uma forma de "vender" algo. Ele possui função social, uma vez que tem o poder de, com argumentos, buscar uma regulação social 
simbólica entre os indivíduos: "A persuasão é elemento indispensável da interação social humana, e se faz presente em todas as culturas" (Roiz, 2002, p. 277 apud Fischer, 2007).

Fischer (2007) defende, ainda, que a persuasão é uma atividade consciente e que tem a intenção de modificação de conduta.

Há muito, os veículos de comunicação já sabem desse fato e por isso deixaram de ser meras fontes de informação e entretenimento. Eles são hoje um canal que liga o sujeito a tudo que o cerca, seja em sua rua, bairro, nação ou em escala global. Sendo assim, tornam-se uma espécie de janela que traz o que está distante para perto do sujeito, ou seja, em que produtos são anunciados, conceitos criados, notícias dadas e comentadas em todo o âmbito da esfera pública. Entende-se por esfera pública, segundo a definição de Taylor 2010, p. 4):

Um espaço comum em que, supostamente, os membros da sociedade se encontram através de uma variedade de meios - imprensa, eletrônica e também encontros face a face - para discutirem assuntos de interesse comum e, deste modo, serem capazes de formar a seu respeito uma mente comum.

A publicidade, nesse contexto, assume papel relevante, uma vez que não só tenta vender ou criar um conceito na mente dos sujeitos, mas interfere na organização e estrutura social, ao mesmo tempo em que é interferida por ela. É, sobretudo, um meio de mediação com a massa, uma ferramenta que leva a mensagem até o indivíduo, em muitos casos servindo para a venda de algo.

Se se entender a palavra vender em toda a sua amplitude, vender seria, inicialmente, um ato comunicativo. A etimologia da palavra remete ao latim vendere, que é, antes de tudo, o ato de expor e elogiar algo. Stanton e Spiro (2000, p. 4) prelecionam que: "o conceito de venda é tão antigo e universo quanto as relações entre os seres humanos. Das simples trocas de mercadorias às avançadas técnicas de persuasão do comprador, percorre-se um longo caminho [...]". 
O entendimento posterior agrega a persuasão do sujeito a ter certo tipo de comportamento ou gerar atitudes. Como afirma Futrell (2003), o conceito de vendas irá se referir a uma comunicação pessoal de informações que visa justamente a persuadir um cliente em potencial a comprar algo (produto, serviço, ideias) que possa atender às suas necessidades. Assim sendo, ao convencer uma mãe da necessidade de vacinar seu filho, a publicidade consegue "vender" a ideia de que é muito melhor cuidar agora do que depois ter um filho doente por negligência. Portanto, se vender é comunicar e persuadir, a publicidade é um dos instrumentos para que isso aconteça.

Tem-se uma visão muito equivocada da publicidade, remetendo a ela a ideia de que sua principal função é promover os interesses do capital. A publicidade só é nociva quando promove coisas nocivas, pois o seu conceito é amoral. A publicidade pensada para o novo tempo tem sido utilizada não apenas vislumbrando o lucro, tem sido levada a superar suas ações tradicionais de venda de produtos e de criação de imagem, passando a assumir papel estratégico para divulgar valores éticos.

O problema então surge da inquietação dos pesquisadores ao perceberem que cotidianamente a publicidade é vista apenas como um instrumento que visa a alavancar vendas ou manipular massas.

[...] a teoria e a análise sociológica dos últimos dez anos têm vindo a desvalorizar o econômico, em detrimento do político, do cultural e do simbólico, têm vindo a desvalorizar os modos de produção em detrimento dos modos de vida. (Santos, 2010, p. 20)

Assim como Santos (2010), estes pesquisadores procuraram trazer a relevância do papel pedagógico da publicidade como algo a ser discutido e ampliado fora das amarras que colocam a publicidade apenas como um artefato mercadológico, tecendo, assim, um novo discurso que atrele suas melhores qualidades a conceitos como educação, pedagogia e desenvolvimento local.

Tais conceitos são, geralmente, desassociados da publicidade, quando não colocados em posições opostas. A educação e a pedagogia, como um campo nobre, podem ser 
afetadsa negativamente pela publicidade e tem pouco ou nada a ser acrescidas por ela. E o desenvolvimento local, como oprimido pela publicidade em massa, dá vazão aos grandes conglomerados nacionais e mundiais em detrimento ao local. Ora, se "vender" é inerente a toda a organização e estrutura social - das quais pertencem a educação e o desenvolvimento local - e a publicidade é um dos instrumentos de comunicação social, não se pode reduzir essa prática aos trâmites comerciais liberais como se somente lá pertencesse.

Neste artigo acredita-se que a importância da função pedagógica da publicidade seja muito maior do que as especulações feitas sem uma pesquisa aprofundada. Acredita-se que o entendimento da função pedagógica da publicidade, tanto sob o olhar dos publicitários quanto dos pedagogos, possua pontos de convergência, resultando, assim, em um entendimento muito próximo um do outro. Ainda se acredita que os conceitos da publicidade utilizados de forma respeitosa podem ser usados na educação, desmistificando a definição de que a publicidade trabalha apenas em favor do capital.

Se se pensar a publicidade como um agente sinérgico com a educação, pedagogia e o desenvolvimento local, deixando de lado a visão meramente instrumental de sua função, ela se eleva a um novo patamar, o de agente transformador, educador e inovador. E se se pensar a educação valendo-se dos princípios da publicidade, chega-se a um mesmo denominador, que é o de uma inovação social que visa ao encontro de saberes distintos na produção de algo novo.

Assim sendo, este estudo se foca em discutir como a publicidade pode ser um agente pedagógico e educacional, tendo como meta o desenvolvimento tanto do ser social, quanto em sua realidade local.

Para o desenvolvimento deste trabalho, buscou-se uma metodologia que abrangesse um estudo referencial, fundamentando-se na pesquisa bibliográfica, em livros, dissertações e teses que possibilitaram o aprofundamento teórico. Também foram feitos levantamentos de artigos nas bases de dados da Scientific Electronic Library Online (SciELO) a partir dos descritores: publicidade, propaganda, educação, pedagogia e desenvolvimento local. 


\section{COMO APRENDEMOS?}

Entender como aprendemos é uma tarefa que tem ocupado diversos pensadores, nos mais diversos campos, desde a própria educação, mas também a Psicologia e a Filosofia. Wood $(1998$, p.18) ressalta que há séculos teorias de como as crianças aprendem tem sido sugeridas e debatidas por esses estudiosos. Este trabalho não se propõe a fazer um estado da arte das diversas abordagens sobre a aprendizagem humana, mas buscar quais delas podem ajudar na proposta de tentar entender a função pedagógica da publicidade.

Segundo Wood (1998), nas décadas de 1960 e 1970 as noções sobre a natureza do pensamento e da aprendizagem foram orientadas pelas teorias de Piaget. O teórico acreditava que abordagens embasadas em estímulo não eram suficientes para explicar um tema tão amplo como o do aprendizado, apenas lidando com fenômenos que só podiam ser diretamente observáveis e manipuláveis. Tal maneira de pensar ajuda quando se refuta a publicidade como um simples instrumento de estímulo ao impulso inconsciente, como se bastasse dizer "compre" e o sujeito comprasse porque aprendeu a fazer assim por condicionamento. E se se levar em consideração a posição de Piaget, pensar uma publicidade que eduque em vez de apenas oferecer um estímulo e esperar uma resposta, pode-se, então, considerá-la uma função pedagógica de fato.

Piaget defendia a ação e a solução de problemas pelo próprio ser, pois agindo no mundo o aprendiz poderia vir a descobrir como controlá-lo. Acreditava que as crianças só aprendiam a partir de sua ação sobre o ambiente. Piaget submete a percepção à ação, ou seja, não se pode agir sobre qualquer coisa sem que primeiro a perceba, e para se perceber algo e dar-lhe um significado é preciso passar por alguns estágios. 0 desenvolvimento cognitivo consiste em adaptações às novas observações e experiências e, após observá-las, as assimila. Piaget (1973, p. 14) expõe a necessidade da assimilação como um dos processos fundamentais para o desenvolvimento cognitivo: 
A importância da noção de assimilação é dupla. De um lado, implica, como acabamos de ver, a noção de significação, o que é essencial, pois todo conhecimento refere-se a significações (índices ou sinais perceptivos, tão importante desde o nível dos instintos, até a função simbólica dos antropoides e do homem, sem falar das abelhas e dos golfinhos). Por outro lado, exprime ofato fundamental de que todo conhecimento está ligado a uma ação e que conhecer um objeto ou acontecimento é utilizá-los, assimilando-os a esquemas de ação.

O pensador ainda ressalta que o desenvolvimento precede a aprendizagem e que todo ser humano passa por vários estágios de desenvolvimento, não se podendo aprender algo de um nível superior (maior dificuldade cognitiva) sem antes ter passado pelos níveis inferiores e tê-los aprendido. A essa teoria se deu o nome de nova teoria da prontidão para a aprendizagem (Wood, 1998, p. 21).

Vale salientar que o pensador, de maneira alguma, nega que a interação com o meio é um fator importantíssimo no aprendizado, uma vez que a interação com o meio social se faz necessária ao desenvolvimento intelectual.

Já o pesquisador Lev Vigotski se afasta de Piaget em algumas questões, mas em outras compartilha da mesma concepção, principalmente no que diz respeito ao desenvolvimento, pois acredita que se trata de um processo dialético e que as crianças são cognitivamente ativas no processo de imitar modelos em seu mundo social.

Com respeito às divergências, o embate acontece principalmente no quesito aprendizado. Vigotski defende que o aprendizado pode anteceder o desenvolvimento.

[...] Não há necessidade de sublinhar que a característica essencial da aprendizagem é que dá lugar à área do desenvolvimento potencial, isto é, faz nascer, estimula e ativa, na criança, processos internos de desenvolvimento no quadro das inter-relações com outros que, em seguida, são absorvidas, no curso do desenvolvimento interno, tornando-se aquisições próprias da criança [...] $A$ aprendizagem, por isso, é um momento necessário e universal para o 
desenvolvimento, na criança, daquelas características humanas não naturais, mas formadas históricamente. (Vygotsky, 1973, p. 161 apud Giusta, 2013)

O autor ainda defende que existem dois níveis de desenvolvimento, que ele denomina de zona de desenvolvimento real e zona de desenvolvimento potencial (ZDP) (Vigostski, 1991). A zona de desenvolvimento real é aquela já consolidada pelo sujeito de tal forma que o torna apto a resolver questões e situações autonomamente, utilizando apenas seu conhecimento.

A zona de desenvolvimento potencial também é determinada pelas habilidades já construídas pelo sujeito, mas ainda se encontra em processo de aprendizado e fixação.

Entre essas duas zonas de desenvolvimento existe uma intermediária, que Vigostki denomina zona de desenvolvimento proximal, que é aquela que, com ajuda externa, pode potencializar o desenvolvimento real.

Vygotski (1991, p. 58) define a ZDP como:

[...] a distância entre o nível de desenvolvimento real, que se costuma determinar através da solução independente de problemas, e o nível de desenvolvimento potencial, determinado através da solução de problemas sob a orientação de um adulto ou em colaboração com companheiros mais capazes.

O conceito de zona de desenvolvimento proximal é muito importante para pesquisar o desenvolvimento e o plano educacional, porque este permite avaliar o desenvolvimento individual. Por esse motivo, provavelmente, é o termo que mais se encaixa na presente pesquisa, pois tem como principal característica a potencialização do aprendizado e, partindo desta ótica, considera-se que a publicidade pode ser uma aliada no desenvolvimento cognitivo de uma pessoa.

Alguns autores mais contemporâneos fazem essa relação entre publicidade e aprendizagem a partir dos conhecimentos elaborados por Vigotski e Piaget, como é o caso de Hoff (2005). A autora corrobora os pensamentos de Piaget quando fala de 
assimilação, mas enfatiza que a mera assimilação nem sempre é suficiente para a construção do conhecimento, alinhando-se, assim, mais ao pensamento vigostkiniano.

A mera assimilação de informação não nos modifica, não nos transforma nem sempre nos liberta para a reflexão e a ação. Ter acesso à informação é o primeiro passo para a construção do conhecimento, que implica a realização de operações mentais como a comparação, a análise, a hierarquização, etc., de modo que seja possivel estabelecer relações entre as muitas informações e chegar a sínteses ou, em outros termos, a opiniões, reflexões e tomadas de decisão. (Hoff, 2005, p. 2)

A autora acrescenta, ainda, que em alguns casos uma pessoa muito bem informada pode ser ao mesmo tempo incapaz de agir ou interferir na realidade, por estar em um nível de mero acúmulo de informação, sem ter produzido o conhecimento. E para que haja produção de conhecimento é preciso estar em constante movimento e desenvolvimento, possibilitando sua atuação como cidadão.

\section{EDUCAÇÃO: FORMANDO O INDIVÍDUO DE AMANHÃ}

Aquí va el texto. Segundo Brandão (1993), a educação é um meio pelo qual o indivíduo tem a oportunidade de desenvolver capacidades psíquicas inatas que ainda não chegaram à perfeição. E a educação está presente em praticamente tudo que nos cerca, que é todo conhecimento adquirido com a vivência em sociedade, seja ela qual for. Assim, o ato educacional se dá no ônibus, em casa, na igreja, na família e todos nós fazemos parte desse processo.

Ninguém escapa da educação. Em casa, na rua, na igreja ou na escola, de um modo ou de muitos, todos nós envolvemos pedaços da vida com ela: para aprender, para ensinar, para aprender-e-ensinar. Para saber, para fazer, para ser ou para conviver, todos os dias misturamos a vida com a educação. (Brandão, 1993, p. 7) 
Libâneo (2002, p. 26) concorda com as ideias de Brandão e define a educação como "[...] fenômeno plurifacetado, ocorrendo em muitos lugares, institucionalizado ou não, sob várias modalidades".

Em várias esferas da sociedade surge a necessidade de disseminação $e$ internalização de saberes e modos de ação (conhecimentos, conceitos, habilidades, hábitos, procedimentos, crenças, atitudes), levando a práticas pedagógicas. Mesmo no âmbito da vida privada, diversas práticas educativas levam inevitavelmente a atividades de cunho pedagógico na cidade, na família nos pequenos grupos, nas relações de vizinhança. (Libâneo, 2002, p. 27)

A educação, para Libâneo, se associa a processos de comunicação e interação pelos quais os membros de uma sociedade assimilam saberes, habilidades, técnicas, atitudes, valores existentes no meio culturalmente organizado e com isso ganham saber necessário para produzir outros saberes, técnicas e valores.

Ainda segundo Coelho e Pisoni (2012, p. 147):

[...] a aprendizagem é um processo contínuo e a educação é caracterizada por saltos qualitativos de um nível de aprendizagem a outro. Isso nos mostra a grande importância das relações sociais e que dois tipos de desenvolvimento foram identificados: o desenvolvimento real que se refere àquelas conquistas que já são consolidadas na criança e que habitualmente costuma-se avaliar a criança somente neste nível, ou seja, somente o que ela já é capaz de realizar e o desenvolvimento potencial, que se refere àquilo que a criança pode realizar com auxílio de outro indivíduo. Neste caso, as experiências são muito importantes, pois ele aprende através do diálogo, colaboração e imitação.

Na educação, o desenvolvimento intermediário entre esses dois níveis possui expressiva atuação, pois o desenvolvimento proximal é aquele em que a criança precisa de apoio para realizar certa tarefa, ou seja, ela irá precisar de alguém com conhecimentos acima dos dela, no caso o professor, para auxiliá-la a passar para a etapa seguinte. 
Outro grande estudioso que compartilha da visão desses autores é Paulo Freire, que defende que o verdadeiro processo de aprendizagem é aquele que tem o poder de transformar o indivíduo. Sendo assim, os saberes ensinados são assimilados e reconstruídos tanto pelos educandos quanto pelos educadores e, partindo dessa reconstrução, tornam-se autônomos, emancipados e questionadores: "Nas condições de verdadeira aprendizagem, os educandos vão se transformando em reais sujeitos da construção e da reconstrução do saber ensinado, ao lado do educador igualmente sujeito do processo" (Freire, 2011, p. 26).

O autor ainda defende que a educação tem que ter caráter problematizador, libertador, acima de tudo visando à transformação de uma realidade opressora em uma realidade igualitária, favorecendo os marginais à sociedade. Também acredita que a educação não deve ser de forma bancária, ou seja, o professor (detentor de todo o conhecimento) deposita no educando todo o seu saber. O educando, por sua vez, recebe-o passivamente. Para Freire:

[...] o educador aparece como seu indiscutível agente, como o seu real sujeito, cuja tarefa indeclinável é "encher" os educandos dos conteúdos de sua narração. Conteúdos que são retalhos da realidade desconectados da totalidade em que se engendram e em cuja visão ganhariam significação. A palavra, nestas dissertações, se esvazia da dimensão concreta que deveria ter ou se transforma em palavra oca, em verbosidade alienada e alienante. Daí que seja mais som que significação, assim, melhor seria dizê-la. (Freire, 1987, p. 33)

É impossível pensar em uma educação problematizadora se não se levar em consideração o rompimento do pensamento da educação bancária. E tal rompimento é necessário, pois:

Desta maneira, o educador já não é o que apenas educa, mas o que, enquanto educa, é educado, em diálogo com o educando que, ao ser educado, também educa. Ambos, assim, se tornam sujeitos do processo em que crescem juntos e em que os "argumentos de autoridade" já não valem. (Freire, 1987, p. 39) 
Quando se pensa então em uma educação que liberta em vez de domesticar, a publicidade pode tornar-se uma aliada, tendo em vista seu potencial de tornar algo público. Muitos têm a visão da publicidade como um instrumento bancário, que visa apenas a incutir na mente de um indivíduo uma ação ou desejo.

\section{PEDAGOGIA: UMA ALIADA DA EDUCAÇÃO}

Quando se fala em pedagogia, o termo comumente se equipara e se confunde com o de educação, mas são termos que, apesar de estarem totalmente ligados, possuem suas particularidades.

Desde a Grécia Antiga o termo pedagogia possui uma referência dúbia, que, segundo Saviani (2007), desenvolve, de um extremo, a reflexão estreita com a filosofia e, de outro extremo, a experiência e a prática, reforçando, assim, a metodologia e a condução da criança. Ora é tratada como arte e ora como metodologia, ainda como arte educativa e não como estudo do fenômeno de educar. O autor não concorda que a pedagogia seja uma arte educativa ou apenas um fenômeno dentro da educação. Para ele:

Na verdade, o conceito de Pedagogia se reporta a uma teoria que se estrutura a partir e em função da prática educativa. A Pedagogia, como teoria da educação, busca equacionar, de alguma maneira, o problema da relação educadoreducando, de modo geral, ou, no caso específico da escola, a relação professoraluno, orientando o processo de ensino e aprendizagem. (Saviani, 2007, p. 102)

Libâneo (2006, p. 6) também conceitua a pedagogia como ciência da educação e definea, ainda, como "um campo de conhecimentos sobre a problemática educativa na sua totalidade histórica e, ao mesmo tempo, uma diretriz orientadora da ação educativa".

A pedagogia, segundo o autor, é a ciência que tem a educação como seu objeto de estudo. Outros campos do saber, como Sociologia, Psicologia, entre outros, podem também se ocupar com problemas relacionados diretamente à educação, mas "é a Pedagogia que pode postular o educativo, propriamente dito, e ser ciência integradora 
dos aportes das demais áreas. Isso não quer dizer, todavia, que ela, por isso, passa ocupar lugar hierarquicamente superior às demais" (Libâneo, 1996, p. 118).

O autor propões que a pedagogia é uma prática humana e social, que transforma os seres humanos no seu cerne, ou seja, estado físico, mental e espiritual, fazendo com que se configure a existência humana, tanto individual, quanto coletiva, e consequentemente são essas as transformações que fazem parte do objeto de estudo da pedagogia. $O$ autor salienta que isso acontece principalmente pela comunicação, pela experiência acumulada ao longo de toda sua evolução. Em resumo, conforme o autor:

A Pedagogia, mediante conhecimentos científicos, filosóficos e técnicoprofissionais, investiga a realidade educacional em transformação, para explicitar objetivos e processos de intervenção metodológica e organizativa referentes à transmissão/assimilação de saberes e modos de ação. Ela visa ao entendimento, global e intencionalmente dirigido, dos problemas educativos e, para isso, recorre aos aportes teóricos providos pelas demais ciências da educação. (Libâneo, 2001, p. 10)

Sendo assim, tanto Libâneo quanto Saviani concordam que educação e pedagogia são termos distintos, que um educa, já o outro estuda o fenômeno de educar. Vale a pena salientar que os dois termos se complementam e por esse motivo são comumente tido como sinônimos.

Paulo Freire (2011) compartilha dos pensamentos dos autores citados e ressalta que pedagogia/educação não é uma doação ou imposição, mas uma devolução dos conteúdos coletados na própria sociedade, que depois de sistematizados e organizados são devolvidos aos indivíduos na busca de uma construção de consciências críticas frente ao mundo.

O autor sugere uma educação ou pedagogia que seja totalmente diferente do que ele mesmo nomeia de bancária, ou seja, o que ensina é o detentor de todo o saber e o que aprende é como um cofrinho onde o saber é apenas depositado, fazendo com que seu senso crítico seja anulado, pois não existe uma discussão na construção desse saber. 
Ladislaw Dawbor compartilha do pensamento de Paulo Freire ao defender que:

A ideia da educação para o desenvolvimento está diretamente vinculada a essa compreensão e à necessidade de se formarem pessoas que amanhã possam participar de forma ativa das iniciativas capazes de transformar o seu entorno, de gerar dinâmicas construtivas. (Dowbor, 2006, p. 76)

Assim sendo, a publicidade pode se tornar uma aliada nesse processo de gerar autonomia e transformação do sujeito, pois seu caráter persuasivo e o seu potencial de difundir ideias e produtos podem se tornar um suporte valioso tanto para a pedagogia quanto para a educação, tendo em vista que, valendo-se da pedagogia, pode-se planejar e estudar processos educativos tendo como suporte a publicidade e a difusão desses processos planejados por meio da educação.

\section{O QUE É PUBLICIDADE?}

De acordo com Sant'Anna (1998), a palavra publicidade é derivada de público (do latim publicus) e significa "a qualidade do que é público", isto é, o ato de tornar público um fato, uma ideia. Pode-se dizer, então, que a palavra publicidade significa, genericamente, divulgar, tornar público. Publicidade é um meio de trazer ao conhecimento público um produto, um serviço ou até uma idéia; e seu objetivo é despertar no público o desejo pelo que foi anunciado.

A publicidade cada dia mais tem se transformado em um dos discursos narrativos que mais contribuem para a construção da subjetividade do homem moderno.

Além de transmitir valores sociais, pessoais e de se constituir em modelo de referência, a publicidade tem ainda a função de demonstração de modelos a serem seguidos, isto é, a apresentação de padrões físicos, estéticos, sensuais, comportamentais aos quais as pessoas devem se amoldar (Marcondes Filho, 1992, p. 77). Ela efetivamente desenvolve uma ação pedagógica, e isso se dá pelo fato de seu caráter persuasivo.

De acordo com Macedo (2010, p. 103), a publicidade vai além do senso comum e pode proporcionar ao sujeito experiências que vão além da compra propriamente dita. 
Apesar do senso comum, sabe-se que a publicidade nem sempre manipula, na forma pejorativa da palavra (sinônimo de enganação), mas motiva, influencia, isto é, desencadeia pensamentos, ideias, que podem proporcionar prazer através das representações dos produtos. E essas representações, sim, poderão acarretar a compra de bens, pois são capazes de interferir diretamente na subjetividade, $e$ isso nada mais é do que o hedonismo autoilusivo a que Campbell se refere, isto é, que os prazeres não vêm somente de experiências concretas, vividas, mas da imaginação, que não deixa de ser uma forma de experiência. Portanto, independentemente de a publicidade acarretar ou não a compra dos produtos, 0 fato de entrarmos em contato com ela já é uma forma de consumo, em que estamos consumindo não bens tangíveis, mas intangíveis. Isso é fundamental para a constituição do homem como sujeito e, por sua vez, pode acarretar o consumo de bens tangíveis.

O discurso persuasivo na publicidade busca, então, criar em seu interlocutor sentimentos e motivações que o levem à tomada de decisão.

Consome-se muito mais do que um mero produto, mas uma infinidade de bens que não são necessariamente produtos palpáveis, mas nem por isso de menos valor.

O "consumo" de anúncios não se confunde com o "consumo" de produtos. Podemos até pensar que o que menos se consome num anúncio é o produto. Em cada anúncio "vende-se" "estilo de vida", "sensações", "emoções", "visões de mundo", "relações humanas", "sistemas de classificação", "hierarquia", em quantidades significativamente maiores que geladeiras, roupas ou cigarros. (Rocha, 1990, p. 27)

Para que uma pessoa seja convencida a consumir ou comprar algo, ainda que seja só uma ideia, é necessário colocar em sua consciência, sucessivamente, quatro estados, a saber: atenção, interesse, desejo e ação (Sant'anna, 1998, p. 91). Quando a publicidade 
influencia o indivíduo de tal forma que consegue levá-lo a esses quatro estados, consegue-se o ápice de uma ação publicitária.

O objetivo da publicidade, além da venda de produtos, serviços e bens simbólicos, é demonstrar modelos a serem seguidos, apresentando, desta forma, um objetivo mais amplo, que consiste em oferecer as vantagens de determinados produtos, e um objetivo implícito, por intermédio do qual flui sua ação pedagógica.

E segundo Castro:

Mais uma vez os pilares publicidade e marketing entram em cena, buscando moldar de forma favorável a percepção da imagem através da qual uma marca venha a ser reconhecida e valorizada. Se antes se vendiam coisas, atualmente se vendem, sobretudo, imagens e modos de ser. Verifica-se um investimento mais sutil do mercado nos próprios processos de subjetivação. Nesse sentido, a mídia desempenha uma função primordial ao veicular $e$ induzir ideias, atitudes $e$ padrões de comportamento que podem servir de modelo para a construção de identidades em nossos días. (Castro, 2008, p. 139)

Sendo assim, a publicidade pode assumir um papel que está além das atribuições que o senso comum lhe concede, assumindo caráter pedagógico quando leva em consideração a persuasão para a propagação de ideias e ações. A publicidade, sendo tratada como um agente de suporte educativo, pode trazer benefícios reais à educação, pois, levando em conta a sua penetração, seja nos lares por meio da televisão (TV), nos carros por intermédio do rádio ou em dispositivos móveis por meio da internet, ela está presente em toda parte, tornando-se um recurso ainda pouco explorado em relação à pedagogia e à educação.

\section{PUBLICIDADE E EDUCAÇÃO: TRILHANDO UM NOVO CAMINHO}

Levando-se em consideração a posição de Paulo Freire (2011), que visa a um empoderamento do cidadão e à construção de seu senso crítico por meio de processos educativos, pensar uma ação publicitária que tenha como meta esses mesmos valores torna-se uma tarefa um tanto pertinente. A publicidade, na maioria das vezes, tende a 
reforçar valores ou desejos que já estão incutidos na pessoa ou lhe apresenta e até cria novas expectativas.

Partindo dessa ótica, a publicidade como uma ferramenta pedagógica/ educacional constitui-se em um vislumbre possível, já que, segundo Baccega (2005), a publicidade pelo seu caráter de anunciadora de novas linguagens e colaboradora no despertar de novas sensibilidades desempenha importante papel no campo da comunicação/educação. A autora salienta que o publicitário exerce papel muito importante quando se pensa em uma articulação entre publicidade e educação.

O publicitário é um comunicador, sujeito que assume o discurso da comunicação, com sua natureza de redesenho dos discursos sociais em circulação. Como enunciatário dos discursos sociais, terá que ter a sensibilidade necessária para reelaborá-los, objetivando a divulgação de um produto, de um serviço, uma ideia ou um comportamento e respeitando o universo social de seus enunciatários. Desse modo ele conseguirá êxito, pois será capaz de construir, no encontro, um território afirmativo, que possibilitará variadas articulações por parte do enunciatário, no percurso da interpretação. (Baccega, 2005, p. 4)

Sampaio (2000) constata que as crianças têm grande facilidade de acreditar no que os adultos Ihes falam. E é nesse ponto que se pode fazer uma ligação com o que diz Vigotski quando defende que a criança deve e pode ser auxiliada para chegar a um estágio mais alto. Esse estágio é a ZDP, é a publicidade, utilizada de forma criativa e responsável e visando à construção do ser social, podendo se tornar um agente facilitador na ZDP, não ocupando o lugar do adulto ou professor, mas auxiliando-o na tarefa de ajudar o indivíduo a superar o estágio em que se encontra.

Elas não são bobas, mas acreditam facilmente em estórias inventadas pelos adultos. Sabem das coisas, mas suas explicações só são capazes de convencer os seus próprios pares. São desprovidas de "malícia", ou seja, não dispõem ainda de conhecimentos amplos sobre os bastidores da vida adulta. (Sampaio, 2000, p. 223) 
A autora ainda recomenda que é necessário repensar até mesmo a programação televisiva visando a uma real educação e que ainda hoje muitos programas têm cunho mais comercial do que educacional.

Negligenciando o preceito constitucional do artigo 221 - que prevê a preferência às finalidades educativas, artísticas, culturais e informativas nas programações de rádio e TV - e na ausência de regulamentação específica sobre o tema, os programas infantis nas emissoras privadas se transformaram em vitrine de productos. (Sampaio, 2009, p. 14)

Paulo Freire, em seu ensaio “Extensão ou comunicação?” (1983), enfatiza que o mundo é da comunicação e a comunicação se dá por intermédio de sujeitos coparticipantes que apresentam reciprocidade entre si. Sendo assim, pensar uma educação que possa abarcar os conceitos da publicidade com o intuito de potencializar as ações do desenvolvimento local passa a fazer um grande sentido, uma vez que a comunicação se faz necessária em quase todos os campos sociais.

Se for levado em consideração que a educação é a bússola que norteia o desenvolvimento de um indivíduo e que a publicidade pode ter importante papel na reverberação de políticas que visem a introjetar novos conceitos a respeito da vida desse mesmo indivíduo, pode-se criar um vínculo com o desenvolvimento, tanto pessoal quanto em seu espaço de convivência.

Ladislau Dowbor faz uma crítica pertinente quanto ao uso da publicidade sem um real comprometimento com o desenvolvimento:

Empresas hoje fornecem software educacional para escolas, com publicidade já embutida, martelando a cabeça das crianças dentro da sala de aula. A televisão submete as nossas crianças (e nós) ao circo de quarta categoria que são os ratinhos de diversos tipos, explicando que está apenas seguindo as tendências do mercado, dando ao povo o que o povo gosta. Se o argumento é válido, porque 
um professor também não passar a ensinar o que os alunos gostam, sem preocupação com a verdade e o nível cultural? (Dowbor, 1999, p. 9-10)

É preciso pensar uma publicidade que seja divergente do que aqui foi citado e que, seguindo a linha de pensamento do autor, consiga gerar um desenvolvimento local, um empoderamento do cidadão, o resgate de seu poder de tomar decisões. Promovendo o desenvolvimento, o cidadão passa a ter participação ativa, já que ocorre o fortalecimento da sociedade civil.

É necessário entender que o desenvolvimento local não está relacionado somente ao crescimento da economia, mas também à melhoria da qualidade de vida e à preservação do meio ambiente. Esses três fatores estão inter-relacionados e são interdependentes.

O aspecto econômico implica aumento da renda e riqueza e também contribui para que sejam criadas melhores condições de trabalho. E havendo melhores condições de se trabalhar, aumenta-se também a geração de riqueza, que tende a contribuir para a melhoria de oportunidades sociais.

Ainda segundo Dowbor (2006), são de extrema importância a informação e a educação, principalmente de nossa juventude, pois ela está em constante contato com as novas tecnologias e com o mundo globalizado, mas o autor defende que, mesmo em contato com essa "globalização", o "local" tem obtido o seu espaço. Basta ver como nas redes sociais cada vez mais os comentários se referem ao local onde vivem os jovens e suas postagens são muitas vezes relacionadas ao desenvolvimento de sua comunidade.

Para Dowbor (2006), quando as pessoas se apropriam do local, ou seja, do lugar que ocupam e com o qual devem desenvolver relação de pertencimento, as mesmas criam uma cultura de desenvolvimento.

É nesse panorama que a escola e a educação desempenham papel primordial, que é o de articuladora e mediadora dos conhecimentos, fazendo com que o interesse pelo desenvolvimento local seja aguçado. 
A educação não pode se limitar a constituir para cada aluno um tipo de estoque básico de conhecimentos. As pessoas que convivem num território têm de passar a conhecer os problemas comuns, as alternativas, os potenciais. A escola passa assim a ser uma articuladora entre as necessidades do desenvolvimento local, $e$ os conhecimentos correspondentes. (Dowbor, 2006, p. 5)

A publicidade se torna uma potencializadora do desenvolvimento local quando utilizada em conjunto com a educação, pois consegue apresentar, seja por meio das redes, da televisão, rádio ou mídia impressa, possibilidades inerentes à realidade vivida por aqueles atores, podendo despertar o sentimento de mudança da realidade, uma vez que tanto a publicidade quanto a educação estão em constante interação com o meio social.

Quando o assunto é estar em constante movimento e interação com o meio social, Baccega (2005) postula que a construção dos sentidos sociais emerge do campo comunicação/educação e que de um lado estão a escola e a família e de outro estão a mídia e, consequentemente, a publicidade.

O desafio, hoje, é a interpretação do mundo em que vivemos, uma vez que as relações imagéticas estão carregadas da presença da mídia. Trata-se de uma construção do mundo altamente influenciada pelos meios de comunicação, que selecionam o que devemos conhecer, os temas a serem pautados para discussão e, mais que isso, o ponto de vista a partir do qual vamos compreender esses temas. Eles se constituem em educadores privilegiados, dividindo as funções antes destinadas à escola. (Baccega, 2005, p. 2)

Isso posto, a autora opina que o papel da escola e, consequentemente, o modo como se educa passa a ter uma nova definição, pois precisa agora incorporar e construir sentidos sociais também se valendo da mídia ou publicidade, uma vez que cada vez mais se tem notado a presença da mesma, seja dentro de casa pela TV, na internet ou rádio.

O Ministério da Educação já tem voltado seus olhos para uma publicidade que eduque em vez de apenas visar ao lucro, que entre pelas portas da casa e da escola trazendo valores e sentido social. 
A autora salienta, então, que:

O papel da escola redefine-se: não basta falar em educação para os meios ou em leitura crítica dos meios, como se os meios de comunicação fossem uma realidade externa, "de fora". A escola precisa não apenas problematizar o conteúdo dos meios, mostrando a interface desse conteúdo com os valores hegemônicos da sociedade e com os interesses que aí residem (ainda que se trate de uma etapa indispensável). Não basta, também, discutir as propostas dos programas midiáticos em confronto com as propostas culturais dos receptores, desvelando as convergências e divergências. Mais que isso: é preciso falar, agora, dessa construção de sentidos sociais que se dá no encontro produtos midiáticos/receptores, no bojo da construção das práticas culturais, em que mídia, escola e família vêm desempenhando importantes papéis, num sólido amálgama. (Baccega, 2005, p. 2)

Tanto a escola quanto a publicidade assumem um novo papel, pois as duas juntando-se e ajudando-se se tornam um elo entre a educação e o desenvolvimento ao sujeito, levando-o a estágios de desenvolvimento mais altos. Segundo Vigotski, seria mais difícil essa transição sem a ajuda externa. Assim sendo, a publicidade de certa forma já faz isso, só que de maneira não sistemática e pensada com caráter educacional, quando entra nas casas informando e apresentando uma gama de produtos e ideias. Isso significa que a publicidade já faz parte do cotidiano de famílias inteiras, está dentro de suas casas diariamente.

Então, pensar na publicidade adentrando as escolas, seja divulgando, seja ensinando conforme uma metodologia preestabelecida, passa a ser uma hipótese viável, pedagógica e, por que não, potencializadora do desenvolvimento humano, social e local.

\section{CONSIDERAÇÕES FINAIS}

A revisão teórica veio confirmar a possibilidade de se utilizar a publicidade como agente da educação e, muito mais que isso, poder se tornar uma ferramenta que educa ao 
mesmo tempo em que potencializa o desenvolvimento local, a partir de ações que envolvam não apenas a comunidade escolar, mas os pais e a comunidade em geral.

Finalizando, acredita-se que esse é um processo que se inicia modestamente, mas que, a começar pelo pesquisador, já causa mudanças na concepção de como a educação pode ser pensada. E espera-se que a partir dessa dissertação novas pesquisas possam ser elaboradas, com o intuito de cada dia se ter uma publicidade que consiga ir além de um mero anúncio.

\section{REFERÊNCIAS}

Baccega, M. A. (2005). O impacto da publicidade no campo comunicação/educação. Caderno de Pesquisa, 1(3), 11-94.

Brandão, C.R. (1993). O que é educação. São Paulo: Brasiliense.

Castro, G. (2008). Mídia, consumo, globalização e contemporaneidade. En M. A. Baccega (org.), Comunicação e culturas do consumo. São Paulo: Atlas.

Coelho, L. e Pisoni, S. (2012). Vygotsky: sua teoria e a influência na educação. Revista e-Ped, 2(1), 144-152.

Dowbor, L. (1999). Tendências da gestão social. Saúde e Sociedade, 8(1), 3-16.

Dowbor, L. (2006). Educação e desenvolvimento local. Instituto Lina Galvani. Disponível em www.linagalvani.org.br/.../Educação\%20e\%20Desenvolvimento\%20Loc

Fischer, M.E. (2007). A persuasão na perspectiva da publicidade: algumas aproximações iniciais. Trabalho apresentado no XXX Congresso Brasileiro de Ciências da Comunicação, Santos, SP. Disponível em http://professor.ucg.br/ siteDocente/admin/arquivosUpload/12031/material/A\%20persuas\%C3\%A30\%20na\%2 Operspectiva.pdf

Freire, P. (1983). Extensão ou comunicação? Rio de Janeiro: Paz e Terra, 1983. 
Freire, P. (1987). Pedagogia do oprimido. Rio de Janeiro: Paz e Terra.

Freire. P. (2011). Pedagogia da autonomia. São Paulo: Paz e Terra.

Futrell, C.M. (2003). Vendas: fundamentos e novas práticas de gestão. São Paulo: Saraiva.

Gil, A. C. (2010). Métodos e técnicas de pesquisa social. São Paulo: Atlas.

Giusta, A. S. (2013). Concepções de aprendizagem e prática pedagógica. Educação em Revista, 29(1). Disponível em http://dx.doi.org/10.1590/S0102-46982013000100003

Hoff, T. M. (2005). O texto publicitário como suporte pedagógico para a construção de um sujeito crítico. Comunicação \& Educação, 12(2), 29-38.

Libâneo, J.C. (2001). Pedagogia e pedagogos: inquietações e buscas. Educar, Curitiba, (17), 153-176.

Libâneo, J.C. (2002). Pedagogia e pedagogos para quê? São Paulo: Cortez.

Libâneo, J.C. (1996). Que destino os educadores darão à Pedagogia? En S. G. Pimenta (org), Pedagogia, ciência da educação? São Paulo: Cortez.

Macedo, D. G. (2010). Consumo, identidade e publicidade: uma relação a ser (re)pensada. Comunicação \& Educação, 15(3), 101-109.

Marcondes Filho, C. (1992). Televisão: a vida pelo vídeo. São Paulo: Moderna.

Piaget, J. (1973). A linguagem e o pensamento da criança. Rio de Janeiro: Fundo de Cultura.

Rocha, E. P. G. (1990). Magia e capitalismo: um estudo antropológico da publicidade. São Paulo: Brasiliense.

Sampaio, I. S. (2000). Televisão, publicidade e infância. São Paulo: Anna Blume.

Sant'anna, A. (1998). Propaganda: teoria, técnica e prática. São Paulo: Pioneira. 
Santos, B. S. (2010). Pela mão de Alice: o social e o político na pós-modernidade. São Paulo: Cortez.

Stanton, W. J. e Spiro, R. (2000). Administração de vendas. Rio de Janeiro: LTC.

Saviani, D. (2007). Pedagogia: o espaço da educação na universidade. Cadernos de Pesquisa, 37(130), 99-134.

Vygotsky, L. S. (1991). A formação social da mente: o desenvolvimento dos processos psicológicos superiores. São Paulo: Martins Fontes.

Wood, D. (1998). Como as crianças pensam e aprendem. São Paulo: Loyola.

Taylor, C. (2010). A esfera pública. Covilhã: Lusosofia. 